\title{
Health-related factors on tobacco consumption in Turkey
}

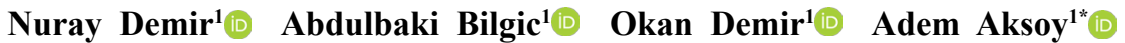

\footnotetext{
${ }^{1}$ Ataturk University, Agricultural Faculty, Department of Agricultural Economics, 25030, Erzurum, Turkey. E-mail: aaksoy@atauni.edu.tr. ${ }^{*}$ Corresponding author.
}

ABSTRACT: In this study, we analyzed the role of individuals' health-related factors along with socio-demographic and economic characteristics on both the likelihood of tobacco consumption and quantity demanded levels using two competitive econometric methods: double hurdle model versus hyperbolic sine double-hurdle model. Statistical tests confirmed the dependency errors between the prevalence rate of smoking and the consumption level, whilst the inverse-hyperbolic sine double-hurdle model data fits best in describing the normalization of the data and the two data generating processes: the probability and consumption levels of cigarettes. Also, the variance-covariance of the selected model as a function of additional exogenous variables are confirmed, while the error terms between the likelihood to smoke and the consumption levels are positive and statistically significant, indicating that holding control variables fixed, the uncontrolled variables out of the system that increase the prevalence rate of smoking also boost the consumption level, or vice versa. Many individual disease variables are significant in both equations, breaking new grounds in literature for identifying how both the prevalence rate of smoking and amount have shaped.

Key words: censoring, double-hurdle, health-related factors, tobacco, Turkey.

Fatores relacionados com a saúde e o consumo de tabaco na Turquia

RESUMO: Neste estudo, analisamos o papel dos fatores relacionados à saúde dos indivíduos, juntamente com as características sóciodemográficas e econômicas, tanto na probabilidade de consumo de tabaco quanto nos níveis de quantidade demandada, usando dois métodos econométricos competitivos: modelo de obstáculo duplo versus modelo de obstáculo duplo seno hiperbólico. Os testes estatísticos confirmaram os erros de dependência entre a taxa de prevalência de tabagismo e o nível de consumo, enquanto o modelo de seno duplo inverso-hiperbólico se ajusta melhor aos dados para descrever a normalização dos dados e os dois processos geradores de dados: os níveis de probabilidade e consumo de cigarros. Também são confirmadas a covariância de variância do modelo selecionado em função de variáveis exógenas adicionais, enquanto os termos de erro entre a probabilidade de fumar e os níveis de consumo são positivos e estatisticamente significativos, indicando que, mantendo variáveis de controle fixas, as variáveis não controladas são do sistema que aumenta a taxa de prevalência do tabagismo e também cresce o nível de consumo, ou vice-versa. Muitas variáveis individuais da doença são encontradas significativamente em ambas as equações, abrindo novos caminhos na literatura para identificar como a taxa de prevalência de tabagismo e a quantidade se moldaram.

Palavras-chave: censo, duplo obstáculo, fatores relacionados à saúde, tabaco, Turquia.

\section{INTRODUCTION}

Recent trends showed that Turkey is one of the largest tobacco-producing and consuming countries in the world. In general, tobacco is consumed worldwide as a cigarette. According to research conducted in recent years, 1.2 billion people above 15 years old smoked one cigarette in the world population, which corresponds to $1 / 3$ of every adult, whilst $80 \%$ of cigarette smokers live in the developing countries (HM, 2007).

Cigarette consumption increased in developing countries as in Turkey, whilst in developed countries, the opposite was the case. For example, during the period 1990-1999, total cigarette consumption decreased by $4.12 \%$ in the world, while in Turkey in the same period the consumption unfortunately raised by $42.18 \%$. The increase in tobacco use in the country has led policy-makers to look for new strategies on how to curb this rise. With 177 countries in 2003, Turkey has signed the first international treaty on tobacco control, the socalled "Framework Convention on Tobacco Control" agreement (OĞUZTÜRK \& GÜLCÜ, 2012; BILGIC et al., 2013; AKSOY et al., 2019). Based on the agreement, the National Tobacco Control Program Action Plan (NTCPAP) 2008 came into force in 2008 in the country. According to this law, smoking is prohibited in all public spaces, hospitals, taxis, sports halls, play parks, and inside and outside 
the school. Later, a new ban has been extended to include restaurants and cafes throughout the country (AKSOY et al., 2019).

In studies on cigarette consumption in the country (BILGIC et al., 2010; KILIC \& OZTURK, 2014; BILGIC \& YEN, 2015; AKSOY et al., 2019), the health factors of individuals or households are often ignored. However, there is a close concurrent relationship between smoking and health factors. While smoking causes many diseases, the opposite is also the case. For example, many chronic diseases (such as cardiovascular, bronchitis and cancer illness) have a negative impact on the probability of smoking consumption and its intensity, while in many diseases (psychological illnesses such as depression, etc.), they are the triggering factors for smoking consumption decision and the amount used. Therefore, this study, which tries to find out the quantitative relationship between cigarette consumption decision/intensity and chronic disease conditions with economic and sociodemographic characteristics of individuals, will be of great importance in establishing more effective health policies in curbing cigarette smoking in the country. To achieve this goal, we first identified factors, including health characteristics that determine the likelihood of tobacco consumption and its intensity (packs), with the help of the generalized hurdle type censored models and then presented the marginal effects of identified factors in the study. In addition, the endogeneity problem caused by health factors in the probability and quantity equations of cigarette consumption was solved by following the literature.

\section{MATERIALS AND METHODS}

\section{Data}

We obtained the data of the Health Research Survey (HRS) conducted by the Turkish Statistics Institution (TSI) in 2012 May-June. The research revealed the socio-demographic features of the surveyed individual along with information on his/her family profile, while the sample size of the study was identified as 35533 individual observations after deleting outliers, irrelevant, and incomplete observations (TSI, 2015).

Table 1 shows the socio-demographic features of individuals. The number of cigarette packs per month was considered as the dependent variable. It has been reported that characteristics of the individuals affect the decision and amount of cigarette consumption (JONES, 1989; TYAS \& PEDERSON, 1998; BILGIC et al., 2010; BILGIC \&Yen, 2015; AKSOY et al., 2019). We are not going to discuss these variables in greater detail here and confine ourselves with Table 1. For example, the monthly cigarette consumption of individuals in the whole population is approximately three packs. Approximately 12 percent of the respondents' smoke. While $46.3 \%$ of the subjects were male, $72.8 \%$ were living in cities, $49.4 \%$ were married, $52 \%$ and $8.5 \%$ were high schools and university graduates, respectively. Approximately $33.2 \%$ and $38.2 \%$ of the subjects consume fruits and vegetables once a day, whilst approximately $13.3 \%$ of them are in the obese group. The highest rate of diseases was observed as hypertension with $10.8 \%$, while the rate of alcohol use among subjects was approximately $7 \%$. Meanwhile, the health questionnaire, unfortunately, does not include the cigarette price variable; and therefore, we assumed that the price does not change for all individuals, and even if the price changes, the constant term in the model captures that effect.

We also checked for multicollinearity among independent variables for the first and second step estimations by calculating the variance inflation factors (VIFs). All VIFs are small, suggesting that multicollinearity was not an issue among explanatory variables in both estimation steps (CHATTERJEE \& HADI, 2006).

\section{Econometric model}

Models vary in explanations for reasons behind zero observations. There are two mechanisms generating the zeros: discrete choice (probit) and censoring (Tobit). In the case of the probit model, zero observations are entirely imputed to a case where tobacco may not be good for some individuals because they are non-users even if tobacco products are free. In contrast, income and cigarette prices become economic obstacles in an individual's budget that hamper attempts to smoke (e.g., censoring). All zeros that represent a corner solution in tobacco consumption are not convincing because some individuals will never consume tobacco products even if they are free (BILGIC et al., 2010; BILGIC \& YEN, 2015; AKSOY et al., 2019). Instead, assuming the dependency of error terms between the participation decision and consumption decision, the double-hurdle model (DH) overcomes this problem in such that zero consumption originate from distinct set of sources: occurrence of non-smoking because of sociological/health-related problems, or simply nonusers of any tobacco products, or non-users during the interview period because of economic obstacles.

Since DH and Inverse Hyperbolic Sine Double-Hurdle (IHS-DH) feature a selection 
Table 1 - Descriptive statistics for variables.

\begin{tabular}{|c|c|c|c|}
\hline Variables & Definition & Mean & Std. Dev. \\
\hline \multirow[t]{2}{*}{ Tobacco } & Monthly consumption (pack per month) & 3.014 & 9.154 \\
\hline & Consumption rate $(\%)$ & 0.120 & 0.325 \\
\hline \multicolumn{4}{|c|}{ - } \\
\hline Gender & 1 if the individual is male, 0 otherwise & 0.463 & 0.498 \\
\hline Urban & 1 if the family lives in urban, 0 otherwise & 0.728 & 0.444 \\
\hline Age25-44 & Individual's age in $25-44$ & 0.280 & 0.449 \\
\hline Age 45-64 & Individual's age in $45-64$ & 0.216 & 0.412 \\
\hline Age $65<$ & Individual's age in $65<$ & 0.091 & 0.288 \\
\hline Marital status & 1 if the individual is married, 0 otherwise & 0.494 & 0.499 \\
\hline Income Source-1 & $\begin{array}{l}1 \text { if the individual receives a salary from the government and/or } \\
\text { private sector or is retired, } 0 \text { otherwise }\end{array}$ & 0.943 & 0.231 \\
\hline Income Source-2 & $\begin{array}{l}1 \text { if the individual receives his income from the mobile property } \\
\text { and/or real estates, } 0 \text { otherwise }\end{array}$ & 0.035 & 0.184 \\
\hline High School & 1 if the individual has a high school diploma, 0 otherwise & 0.520 & 0.499 \\
\hline College Graduate & $\begin{array}{c}1 \text { if the individual has a community college/college diploma, } 0 \\
\text { otherwise }\end{array}$ & 0.085 & 0.280 \\
\hline Walk & Number of days per week spent walking for at least $10 \mathrm{~min}$ & 2.449 & 3.065 \\
\hline Stairs & 1 if the individual climbs stairs without any help, 0 otherwise & 0.613 & 0.486 \\
\hline Fruit1 & 1 if the individual consumes fruits twice a day, 0 otherwise & 0.075 & 0.264 \\
\hline Fruit2 & 1 if the individual consumes fruits once a day, 0 otherwise & 0.332 & 0.471 \\
\hline Fruit3 & $\begin{array}{c}1 \text { if the individual consumes fruits at least four times a week, } 0 \\
\text { otherwise }\end{array}$ & 0.155 & 0.362 \\
\hline Vegetable1 & 1 if the individual consumes vegetables twice a day, 0 otherwise & 0.097 & 0.296 \\
\hline Vegetable2 & 1 if the individual consumes vegetables once a day, 0 otherwise & 0.382 & 0.486 \\
\hline Vegetable3 & $\begin{array}{c}1 \text { if the individual consume vegetables at least four times a week, } 0 \\
\text { otherwise }\end{array}$ & 0.150 & 0.357 \\
\hline BMI Grp2 & 1 if the BMI for an individual is $30-40,0$ otherwise & 0.099 & 0.299 \\
\hline BMI Grp3 & 1 if the BMI for an individual is greater than 40,0 otherwise & 0.034 & 0.182 \\
\hline BMI & Body mass index for individuals (\#) & 26.023 & 4.134 \\
\hline \multicolumn{4}{|c|}{ 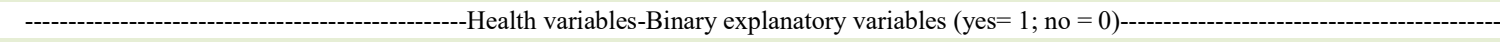 } \\
\hline Hypertension & 1 if the individual has a hypertension disease, 0 otherwise & 0.108 & 0.311 \\
\hline Rheumatism & 1 if the individual has a rheumatism disease, 0 otherwise & 0.067 & 0.251 \\
\hline Diabetes & 1 if the individual has a diabetes disease, 0 otherwise & 0.054 & 0.226 \\
\hline Calcification & 1 if the individual has a calcification disease, 0 otherwise & 0.005 & 0.221 \\
\hline Ulcer & 1 if the individual has an ulcer disease, 0 otherwise & 0.051 & 0.220 \\
\hline Asthma & 1 if the individual has an asthma disease, 0 otherwise & 0.034 & 0.183 \\
\hline Allergy & 1 if the individual has an allergy, disease 0 otherwise & 0.025 & 0.156 \\
\hline Thyroid & 1 if the individual has a thyroid disease, 0 otherwise & 0.021 & 0.145 \\
\hline Migraine & 1 if the individual has a migraine disease, 0 otherwise & 0.035 & 0.184 \\
\hline Sinusitis & 1 if the individual has a sinusitis disease, 0 otherwise & 0.030 & 0.171 \\
\hline Depression & 1 if the individual has a depression disease, 0 otherwise & 0.024 & 0.153 \\
\hline Alcohol & 1 if the individual is consumption, 0 otherwise & 0.068 & 0.252 \\
\hline Medicine & $\begin{array}{c}1 \text { if the individual has on the medication more than a year, } 0 \\
\text { otherwise }\end{array}$ & 0.212 & 0.408 \\
\hline Family Medicine & $\begin{array}{l}1 \text { if the individual receives health care from a family medicine health } \\
\text { care services, } 0 \text { otherwise }\end{array}$ & 0.449 & 0.497 \\
\hline Bedside Treatmnt & $\begin{array}{l}1 \text { if the individual received a bedside treatment in the last } 12 \text { months, } \\
\qquad 0 \text { otherwise }\end{array}$ & 0.118 & 0.739 \\
\hline Prev. Health Care & $\begin{array}{l}1 \text { if the individual receives preventive health care services, } 0 \\
\text { otherwise }\end{array}$ & 0.030 & 0.171 \\
\hline \multicolumn{4}{|c|}{ 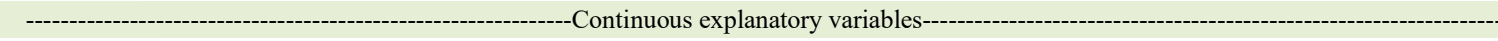 } \\
\hline Income & Family real monthly income in TL/1000 & 1306.728 & 645.088 \\
\hline Diseases & The number of diseases (\#) & 0.780 & 1.537 \\
\hline \# of obs. & Number of observations & \multicolumn{2}{|c|}{35533} \\
\hline
\end{tabular}


(or first-hurdle) equation for the binary outcome variable $d_{i}$ and a level (second-hurdle) equation for the level outcome variable (packs per month) $y_{i}$ for each observation $i$ such that $d_{i}=1$ if $y_{i}>0$ and $d_{i}$ $=0$ otherwise, we began with specifying the latent equations for the two corresponding latent variables, $d_{i}^{*}$ and $y_{i}^{*}$ as:

$d_{i}^{*}=z_{i}^{\prime} \alpha+u_{1 i}$

$y_{i}^{*}=x_{i}^{\prime} \beta+u_{2 i}$

where $z_{i}$ and $x_{i}$ are vectors of explanatory variables affecting the decision and outcome variables, respectively, $\alpha$ and $\beta$ are conformable parameter vectors, and the random error terms $\left[u_{1 i}, u_{2 i}\right]^{\prime}$ are distributed as bivariate normal with zero means, variances $\left[1, \sigma_{i}^{2}\right]^{\prime}$, and correlation $\rho$, viz.,

$\left[\begin{array}{l}u_{1 i} \\ u_{2 i}\end{array}\right] \sim \mathrm{N}\left(\left[\begin{array}{l}0 \\ 0\end{array}\right],\left[\begin{array}{cc}1 & \rho \sigma_{i} \\ \rho \sigma_{i} & \sigma_{i}^{2}\end{array}\right]\right)$

We will present only the IHS-DH model, which is formed by

$T\left(y_{i}\right)=x_{i}^{\prime} \beta+u_{2 i}$ if $z_{i} \alpha+u_{1 i}>0$ and $x_{i}^{\prime} \beta+u_{2 i}>0=$ otherwise

where $T\left(y_{i}\right)=\gamma^{-1} \sinh ^{-1}\left(\gamma y_{i}\right)=\gamma^{-1} \log \left[\gamma y_{i}+\left(\gamma^{2} y^{2}+1\right)^{1 / 2}\right]$, where $\gamma$ is the crucial new parameter that extends the DH model. We considered the IHS transformation on the dependent variable to accommodate non-normal and heteroscedastic error terms. The transformation approaches linearity $\left(T\left(y_{i}, \gamma\right)=y_{i}\right)$ for a larger proportion of its domain as $\gamma$ approaches zero and approaches a logarithmic function (e.g., $\left.\log \left(2 \gamma y_{i}\right)\right)$ as $\gamma$ increases. In addition, the transformation is scale-invariant and is well suited for handling extreme values for $y_{i}$ which minimizes the impact of positive skewness in the data.

The sample likelihood function for the

IHS-DH is

$$
\begin{gathered}
L=\prod_{y_{i}=0}\left[1-\Psi\left(z_{i}^{\prime} a, x_{i}^{\prime} \beta / \sigma_{i}, \rho\right)\right] \\
x \prod_{y_{i}>0}\left[\left(1+\gamma^{2} y_{i}^{2}\right)^{-1 / 2} \frac{1}{\sigma_{i}} \phi\left[\frac{T\left(y_{i}\right)-x_{i}^{\prime} \beta}{\sigma_{i}}\right] \Phi\left[\frac{z_{i}^{\prime} a+\rho\left[T\left(y_{i}\right)-x_{i}^{\prime} \beta\right] / \sigma_{i}}{\left(1-\rho^{2}\right)^{1 / 2}}\right]\right.
\end{gathered}
$$

where $\Phi$ and $\Psi$ are the univariate and bivariate standard normal cumulative distribution functions, respectively, and $\phi$ is the univariate standard normal probability density function. Multiplicative heteroscedasticity is integrated into all models by specifying the error variance as a function of variables $w_{i}, \sigma_{i}=\exp \left(w_{i}{ }^{\prime} \theta\right)$. Here, we assumed $w$ as a function of the individual's alcohol use status, income, total number of diseases, and body mass index variable. In addition, using the Probit model, each binary disease variable including alcohol use was assumed as a function of some characteristics of individuals and their generalized residual variables were then retrieved. Then, both the binary disease variables and their generalized residual variables (e.g., $\mathrm{U}_{\mathrm{i}}$ in Table 2) were used together in the smoking consumption decision and level equations to clean down the inherited endogeneity problem.

While the superiority of the two models (DH versus IHS-DH) and the independence tests between the probability of smoking and consumption in each model were determined with the help of one of the three conventional tests (e.g., Wald, Likelihood Ratio, or Lagrangian Multiplier test). Also, the marginal effects of exogenous variables on the probability, conditional and unconditional consumption levels are obtained for each model. Delta method was used for standard errors. We skip lengthy derivations of marginal effects here but they are well documented in LIMDEP 10's manual documents.

\section{RESULTS AND DISCUSSION}

Before discussing the results, we conducted several specification tests here. First, the conventional independent $\mathrm{DH}$ model was rejected in favor of the dependent DH model (Wald=97.55, $\mathrm{df}=1, \mathrm{P}<0.000$ ). Secondly, testing the IHS-DH model against the DH model (e.g., $\gamma=0$ ), we rejected the null hypothesis that the data is suited for the dependent $\mathrm{DH}$ model (Wald=15.99, $\mathrm{df}=1, \mathrm{P}<0.001$ ). We also rejected the null hypothesis that the independent IHS-DM model is suited for the data (Wald $=518.12, \mathrm{df}=2, \mathrm{P}<0.000$ ). Lastly, in terms of testing for homoscedasticity of the error terms of the model (e.g., $\theta=0$ ), the test result favored the heteroscedasticity form of the error terms.

Most of the parameter estimates from maximizing the log-likelihood function for each model are consistent with prior expectations. However, given the parameters at convergence levels do not reflect the unitary (marginal) impact of an exogenous variable on the dependent variable when an exogenous variable moves from one stage to another. The study presents the marginal effects of independent variables on the quantity demanded packs of cigarettes for the IHS-DH model in Table 2. Since the IHS-DH model outperforms the conventional $\mathrm{DH}$ model with dependence between the error terms and signs of most of the variables in both models equivalent to the probability, conditional and unconditional mean levels, we focused on the discussion of the marginal effects of the IHS-DH model only. In the subsequent sections, the discussion was divided into two subcategories as effects of socio-demographic and economic and disease factors, respectively. 
Table 2 - Parameter estimates of MLE for IHS-DH model.

\begin{tabular}{|c|c|c|c|c|c|c|}
\hline \multirow[t]{2}{*}{ Variables } & \multicolumn{2}{|c|}{----------Probability Level--------- } & \multicolumn{2}{|c|}{----------'Consumption Level---------- } & \multicolumn{2}{|c|}{----------------Heteroscedasticity--------- } \\
\hline & Coefficient & $\mathrm{t}$-value & Coefficient & t-value & Coefficient & $\mathrm{t}$-value \\
\hline Constant & $-3.076^{* * *}$ & -45.01 & 2.045 & 0.70 & - & - \\
\hline Gender & $0.837^{* * *}$ & 21.09 & $6.593^{* * *}$ & 5.27 & - & - \\
\hline Urban & $0.114^{* * *}$ & 4.24 & 0.022 & 0.09 & - & - \\
\hline Age25-44 & $1.111^{* * *}$ & 23.26 & $7.326^{* * *}$ & 4.79 & - & - \\
\hline Age $45-64$ & $1.109^{* * *}$ & 19.00 & $8.199^{* * *}$ & 4.97 & - & - \\
\hline Age65< & $0.792^{* * *}$ & 9.21 & $5.363^{* * *}$ & 3.92 & - & - \\
\hline Marital status & $-0.137^{* * *}$ & -4.55 & $-1.198^{* * *}$ & -3.44 & - & - \\
\hline Income Source-1 & - & - & -0.290 & -0.71 & - & - \\
\hline Income Source-2 & - & - & -0.554 & -1.25 & - & - \\
\hline High School & $0.702^{* * *}$ & 16.32 & $2.267^{* * *}$ & 2.60 & - & - \\
\hline College Graduate & $0.522^{* * *}$ & 8.34 & 0.755 & 0.93 & - & - \\
\hline Hypertension & $-0.654^{* * *}$ & -3.05 & -2.458 & -1.13 & - & - \\
\hline Rheumatism & -0.019 & -0.08 & -0.882 & -0.35 & - & - \\
\hline Diabetes & $-1.135^{* * *}$ & -3.61 & -3.905 & -1.23 & - & - \\
\hline Calcification & 0.261 & 0.83 & 0.299 & 0.09 & - & - \\
\hline Ulcer & $-0.820^{* *}$ & -2.28 & $-5.459^{*}$ & -1.68 & - & - \\
\hline Asthma & 0.332 & 0.72 & $-11.559^{* * *}$ & -2.75 & - & - \\
\hline Allergy & $-1.908^{* * *}$ & -3.15 & $-13.014^{* *}$ & -2.07 & - & - \\
\hline Thyroid & $1.858^{* * *}$ & 3.83 & $9.855^{* *}$ & 2.00 & - & - \\
\hline Migraine & 0.098 & 0.27 & -0.779 & -0.22 & - & - \\
\hline Sinusitis & $-2.518^{* * *}$ & -4.24 & $-15.767^{* * *}$ & -2.62 & - & - \\
\hline Depression & $0.753^{*}$ & 1.71 & 5.392 & 1.40 & - & - \\
\hline Alcohol & $-0.688^{* * *}$ & -4.11 & -2.449 & -1.47 & -0.088 & -2.98 \\
\hline Medicine & $-0.061^{* *}$ & -2.34 & -0.121 & -0.50 & - & - \\
\hline Family Medicine & $0.144^{* * *}$ & 4.40 & $0.619^{*}$ & 1.84 & - & - \\
\hline Bedside Treatmnt & 0.010 & 0.79 & 0.155 & 1.07 & - & - \\
\hline Prev. Health Care & 0.066 & 1.26 & -0.432 & -0.91 & - & - \\
\hline Walk & 0.003 & 0.92 & -0.042 & -1.46 & - & - \\
\hline Stairs & $0.300^{* * *}$ & 8.09 & $1.051^{* *}$ & 2.26 & - & - \\
\hline Fruit1 & $-0.308^{* * *}$ & -6.74 & $-1.697^{* * *}$ & -3.29 & - & - \\
\hline Fruit2 & $-0.324^{* * *}$ & -10.22 & $-2.133^{* * *}$ & -4.26 & - & - \\
\hline Fruit3 & $-0.202^{* * *}$ & -5.89 & $-1.305^{* * *}$ & -3.35 & - & - \\
\hline Vegetable1 & $0.358^{* * *}$ & 8.21 & $1.645^{* * *}$ & 2.76 & - & - \\
\hline Vegetable2 & $0.391^{* * *}$ & 9.54 & $1.652^{* * * *}$ & 2.98 & - & - \\
\hline Vegetable3 & $0.285^{* * *}$ & 6.99 & $0.848^{*}$ & 1.89 & - & - \\
\hline BMI Grp2 & $-0.067^{* *}$ & -2.05 & 0.135 & 0.43 & - & - \\
\hline BMI Grp3 & -0.014 & -0.23 & $1.659^{* * *}$ & 2.58 & - & - \\
\hline Income & - & - & 0.001 & 0.40 & -0.004 & -2.37 \\
\hline Diseases & - & - & - & - & 0.003 & 0.40 \\
\hline BMI & - & - & - & - & 0.001 & 0.31 \\
\hline U1 & $0.308^{* * *}$ & 2.66 & 1.176 & 1.04 & - & - \\
\hline $\mathrm{U} 2$ & 0.088 & 0.70 & 0.780 & 0.66 & - & - \\
\hline U3 & $0.511^{* * *}$ & 3.19 & 1.635 & 1.03 & - & - \\
\hline $\mathrm{U} 4$ & -0.127 & -0.84 & 0.022 & 0.01 & - & - \\
\hline U5 & $0.475^{* * *}$ & 2.76 & $2.968^{*}$ & 1.90 & - & - \\
\hline U6 & -0.167 & -0.79 & $5.413^{* * * *}$ & 2.86 & - & - \\
\hline U7 & $0.842^{* * *}$ & 3.17 & $5.724^{* *}$ & 2.08 & - & - \\
\hline U8 & $-0.820^{* * *}$ & -3.72 & $-4.794^{* *}$ & -2.12 & - & - \\
\hline U9 & -0.001 & 0.00 & 0.430 & 0.26 & - & - \\
\hline U10 & $1.170^{* * *}$ & 4.39 & $7.239^{* * *}$ & 2.69 & - & - \\
\hline U11 & 0.214 & -1.13 & -1.032 & -0.63 & - & - \\
\hline U12 & $0.800^{* * *}$ & 9.01 & $3.649^{* * *}$ & 2.89 & - & - \\
\hline Sigma & $7.202^{* * *}$ & 5.59 & & & & \\
\hline Rho & $0.750^{* * *}$ & 9.88 & & & & \\
\hline Gamma & $0.035^{* * *}$ & 4.00 & & & & \\
\hline Log Likelihood & -24168.899 & & & & & \\
\hline
\end{tabular}

*** ,** and * show statistically significance levels at $\% 1, \% 5$, and $\% 10$, respectively. 
The impacts of socio-demographic and economic factors

Considering the marginal effects of the independent variables on both the probability of cigarette consumption and quantity demanded levels of cigarette packs (Table 3), it indicated that men have the tendency to consume tobacco more (12.7\%) than women. When we look at the conditional and unconditional average tobacco consumption level; results showed that men consume approximately 49.38 and 3.24 packs of a cigarette than women, respectively. Our results coincided with previous studies (GATS, 2012; BILGIC et al., 2010; WHO, 2013 BILGIC et al., 2010; BILGIC et al., 2013; BILGIC \&YEN, 2015; AKSOY et al., 2019).

The place where people live is an important factor in the creation of their lifestyles and habits. People living in cities see smoking as a supporting tool to overcome the cost of living in the city and the pressure, rapid action and stress developed accordingly (JONES, 1989). From this point of view, people living in cities tend to smoke $1.7 \%$ more than their peers in rural areas and consume 0.33 packs more per month in the entire population (e.g., unconditional level).

Our results of both the probability and mean levels echoed with previous findings in the country (BILGIC et al., 2013; BILGIC \&YEN, 2014). These studies identified that people living in rural areas are generally engaged in agriculture and cannot get enough income and hence struggle with living conditions in their residing areas (rural). These people are also usually unaware of their psychological problems even if they have or do not seek assistance to solve such problems (LAMBERT \&AGGER, 1999) and thus consume more cigarettes than those living in the urban areas to mitigate their problems (BILGIC et al., 2013). In addition, in the Turkish community structure, rural residents may have deeper relationships than those living in cities, so smoking treats between each other seem very likely, and at the same time, too much free time in rural areas may trigger cigarette consumption.

According to the WHO classification 1524 age range is considered as a youth, 25-44 as an adult, 45-59 as middle age, 60-74 as old age, 75-89 as elderly and 90 and over as senility (WHO, 2013). Compared to the reference group (15-24), individuals in the other three age groups (25-44, 45-64, and $65>$, respectively) were both likely to consume and demanded more cigarettes. However, as age increases, both the probability level and consumption amount wiped out. Stress and depression, changes due to lifestyles, past failures, and spending more time out due to work pressures increase cigarette smoking among adults. Our results echoed with previous findings (GARCIA \&LABEAGA, 1996; SHAIK \&TEPOJI, 2013; YEN, 2005b). It has further been identified that those who are single smoke more than married people for they spend more time in and around their environment (BILGIC et al., 2010). In addition, smoker and married woman usually quit smoking because of pregnancy and give up smoking when there is a child at home (HISCOCK et al., 2012) and married couples support each other in social terms to resist smoking (WALDRON \& LYE, 1989; LINDSTRÖM et al., 2000).

Education is the most important determinant of socio-economic criteria for smoking. There is a positive relationship between education variables and the probability of smoking in the study. Compared to the primary education group (reference group), the prevalence of cigarette smoking was observed as $9.5 \%$ and $4.7 \%$ among high school and university graduates, respectively. On the contrary, previous findings reported that there is be an inverse relationship between education level and cigarette consumption levels (YEN, 2005b; MACÍAS et al., 2013; BILGIC \&Yen, 2014). In this context, it is necessary to include public service announcements and information on the harmful effects of smoking on human health and job productivity in both visual and printed media as a tool to curb smoking. Moreover, children in primary and high schools should be sensitized on these issues with more permanent and effective methods.

Fruits and vegetables are important building blocks in human diets. It has been identified in the study that individuals who consumed fruits frequently have a lesser tendency to smoke $(4.6 \%$ less). Our findings coincided with previous findings indicating that smoking decreases in individuals who consume fruits a lot, less among frequent users (e.g., once a week) as compared to non-fruit users (PALANIAPPAN et al., 2001). The results showed that people who consume fruits in high quantities in the country are among those who are better educated with good well-being, whilst consumers of vegetables might be among low-income and less educated families, thus were more likely to smoke and consumed more packs of cigarettes.

There is an inverse proportion between measuring living conditions, education, employment status, income, and smoking (CAVELAARS et al., 2000). Our results showed that as a person's income increases, the probability to consume cigarette 
Table 3 - Marginal effects from the inverse hyperbolic sine double hurdle model.

\begin{tabular}{|c|c|c|c|c|c|c|}
\hline \multirow[t]{2}{*}{ Variables } & \multicolumn{2}{|c|}{--------Probability Level------- } & \multicolumn{2}{|c|}{----------Consumption Level----------- } & \multicolumn{2}{|c|}{------Unconditional Level-----. } \\
\hline & Coefficient & Std. Error & Coefficient & Std. Error & Coefficient & Std. Error \\
\hline Gender & $0.127^{* * *}$ & 0.006 & $49.380^{* * *}$ & 12.391 & $3.242^{* * *}$ & 0.186 \\
\hline Urban & $0.017^{* * *}$ & 0.004 & -1.895 & 2.310 & $0.331^{* * *}$ & 0.095 \\
\hline Age25-44 & $0.168^{* * *}$ & 0.007 & $51.516^{* * *}$ & 15.084 & $4.125^{* * *}$ & 0.237 \\
\hline Age45-64 & $0.168^{* * *}$ & 0.008 & $60.143^{* * *}$ & 16.240 & $4.230^{* * *}$ & 0.273 \\
\hline Age65< & $0.120^{* * *}$ & 0.013 & $38.097^{* * *}$ & 13.185 & $2.959^{* * *}$ & 0.334 \\
\hline Marital status & $-0.020^{* * *}$ & 0.004 & $-9.247^{* * *}$ & 3.310 & $-0.548^{* * *}$ & 0.108 \\
\hline Income Source-1 & -0.001 & 0.005 & -2.855 & 4.029 & -0.036 & 0.051 \\
\hline Income Source-2 & -0.001 & 0.001 & -5.454 & 4.372 & -0.070 & 0.056 \\
\hline High School & $0.106^{* * *}$ & 0.006 & 9.302 & 8.483 & $2.308^{* * *}$ & 0.179 \\
\hline College Graduate & $0.079^{* * *}$ & 0.009 & -2.236 & 7.762 & $1.598^{* * *}$ & 0.233 \\
\hline Hypertension & $-0.099^{* * *}$ & 0.032 & -12.070 & 20.166 & $-2.194^{* * *}$ & 0.767 \\
\hline Rheumatism & -0.003 & 0.039 & -8.311 & 23.488 & -0.169 & 0.899 \\
\hline Diabetes & $-0.172^{* * *}$ & 0.047 & -17.403 & 29.800 & $-3.761^{* * *}$ & 1.113 \\
\hline Calcification & 0.039 & 0.047 & -1.894 & 32.324 & 0.790 & 1.106 \\
\hline Ulcer & $-0.124^{* *}$ & 0.054 & -38.528 & 29.920 & $-3.052^{* *}$ & 1.258 \\
\hline Asthma & 0.050 & 0.070 & $-119.922^{* * *}$ & 39.446 & -0.505 & 1.581 \\
\hline Allergy & $-0.289^{* * *}$ & 0.092 & -92.735 & 58.534 & $-7.137^{* * *}$ & 2.177 \\
\hline Thyroid & $0.282^{* * *}$ & 0.073 & 62.565 & 45.799 & $6.594^{* * *}$ & 1.731 \\
\hline Migraine & 0.014 & 0.055 & -9.496 & 32.537 & 0.185 & 1.331 \\
\hline Sinusitis & $-0.382^{* * *}$ & 0.090 & $-108.529^{*}$ & 55.426 & $-9.241^{* * *}$ & 2.144 \\
\hline Depression & $0.114^{*}$ & 0.066 & 39.115 & 35.574 & $2.850^{*}$ & 1.526 \\
\hline Alcohol & $-0.104^{* * *}$ & 0.025 & 14.215 & 15.852 & $-1.963^{* * *}$ & 0.588 \\
\hline Medicine & $-0.009^{* *}$ & 0.003 & 0.062 & 2.240 & $-0.192^{* *}$ & 0.092 \\
\hline Family Medicine & $0.021^{* * *}$ & 0.004 & 3.429 & 3.151 & $0.492^{* * *}$ & 0.116 \\
\hline Bedside Treatment & 0.001 & 0.002 & 1.337 & 1.368 & 0.050 & 0.047 \\
\hline Prev. Health Care & 0.010 & 0.008 & -5.490 & 4.354 & 0.137 & 0.185 \\
\hline Walk & 0.001 & 0.001 & $-0.472^{*}$ & 0.264 & 0.003 & 0.011 \\
\hline Stairs & $0.045^{* * *}$ & 0.005 & 4.780 & 4.438 & $0.997^{* * *}$ & 0.135 \\
\hline Fruit1 & $-0.046^{* * *}$ & 0.006 & $-10.989^{* *}$ & 4.935 & $-1.102^{* * *}$ & 0.161 \\
\hline Fruit2 & $-0.049^{* * *}$ & 0.004 & $-14.993^{* * *}$ & 4.864 & $-1.202^{* * *}$ & 0.119 \\
\hline Fruit3 & $-0.030^{* * *}$ & 0.005 & $-9.101^{* *}$ & 3.706 & $-0.747^{* * *}$ & 0.122 \\
\hline Vegetable1 & $0.054^{* * *}$ & 0.007 & $9.563^{*}$ & 5.674 & $1.238^{* * *}$ & 0.179 \\
\hline Vegetable2 & $0.059^{* * *}$ & 0.006 & $9.021^{*}$ & 5.311 & $1.334^{* * *}$ & 0.151 \\
\hline Vegetable3 & $0.043^{* * *}$ & 0.006 & 3.058 & 4.224 & $0.929^{* * *}$ & 0.147 \\
\hline BMI Grp2 & $-0.010^{* *}$ & 0.004 & 2.577 & 2.895 & -0.176 & 0.116 \\
\hline BMI Grp3 & -0.002 & 0.009 & $16.603^{* * *}$ & 6.017 & 0.168 & 0.221 \\
\hline Income & 0.001 & 0.001 & $0.012^{* *}$ & 0.006 & $0.001^{*}$ & 0.000 \\
\hline Diseases & -0.001 & 0.001 & -0.886 & 2.238 & -0.011 & 0.028 \\
\hline BMI & -0.001 & 0.001 & -0.200 & 0.640 & -0.002 & 0.008 \\
\hline
\end{tabular}

${ }^{* * *},{ }^{* *}$, and ${ }^{*}$ show statistically significance levels at $\% 1, \% 5$, and $\% 10$, respectively. 
decreases by $0.1 \%$, whilst the monthly conditional and unconditional average cigarette consumption decrease by 0.01 and 0.001 packs, respectively.

The two variables we included in the prevalence rate of the smoking equation to overcome an identification problem were Body Mass Indices (BMIs). Their direct effects on the prevalence rate of smoking were negative, though an overweight BMI variable (BMI $>40)$ is insignificant. This variable was subsequently positive though it has an indirect effect on the conditional level of the monthly cigarette packs, indicating that overweighed people tend to smoke more than those who were identified as non-obese $(\mathrm{BMI}<30)$. Indirect effects of BMI and the number of diseases on both the prevalence rate of smoking and the consumption levels were found insignificant.

\section{The impacts of diseases}

Many studies identified that smoking leads to serious diseases that result in death (JEE et al., 2004). In this study, a person's hypertension, rheumatism, diabetes, calcification, ulcer, asthma, allergy, thyroid, migraine, sinusitis and depression, alcohol use and benefiting from preventive health services have been included in the analysis. People diagnosed with diabetes tend to consume fewer cigarettes $(17.2 \%)$ and also demand less packs of a cigarette (3.76) than those who do not have such illnesses. This result indicated that people with diabetes may control coronary disease, with the view that cigarette smoking is a primary risk factor of the disease thus reducing both the prevalence of smoking and the quantity (packs) of cigarette consumed. A study reported that gastric ulcer is twice more likely to be seen among smokers than non-smokers (WHO, 2013). The prevalence of smoking (12.4\%) and the unconditional mean levels of monthly cigarette packs (3.05) get lower with ulcer patients as expected.

Even if a person's asthma condition subsides in expectations due to a reduction in monthly conditional and unconditional mean levels of cigarette packs, the parameter on the unconditional mean level has no statistical significance. Interestingly, among all diseases, the impact of this disease on the conditional mean level of cigarette packs is the greatest, indicating that the quantity demanded of cigarette packs is less demanded among people who are diagnosed with asthma. Allergy significantly reduces the prevalence of smoking $(28.9 \%)$ and the unconditional mean level of cigarette packs (7.14). Similarly, both smoking prevalence rate $(38.2 \%)$ and the conditional/unconditional mean packs (108.53 and 9.24, respectively) decrease among people who are diagnosed with sinusitis disease. Smoking causes the cilia (e.g., the tiny hair-like structures that clean our nose, sinuses, and lungs of airborne particulate matter, bacteria, and mucus) to stop functioning, with victims prone to increased infections of the lungs and sinuses (JEE et al., 2004). Despite this, the thyroid status of a person interestingly increases the likelihood of smoke $(28.2 \%)$ and the monthly unconditional mean level of cigarette packs (6.59). Similarly, individuals who have been treated from depression show an increased tendency to consume cigarette consumption (11.4\%) than those who do not have such disease, whilst people also smoke more cigarettes at unconditional mean levels (2.85). Individuals who are more than a year on medication tend to curb smoking $(0.9 \%)$ and demand fewer packs of consumption with an unconditional mean of 0.19 packs as expected. Interestingly, it has further been found that individuals who are provided with family medicine tended to smoke more than those who do not receive it $(2.1 \%)$ and that they would smoke more cigarettes (unconditional mean level of 0.49 packs per month). Family medicine health support services involve chronic disease follow-ups, contagious disease follow-ups, training, and support services.

As the unaided walking and unaided ability to start climbing and descending gest easier, an individual's likelihood to smoke cigarettes increases by $0.1 \%$ and $4.5 \%$, respectively, though the former is statistically insignificant. However, as the unaided walking improves, reduced monthly cigarette consumption is observed (e.g., for conditional and unconditional averages with approximately 4.78 and 0.99 packs; although, the latter is statistically insignificant. There are several possible reasons why physical activity will serve as a protective measure of smoking behavior. Physical activity has a negative relationship with depression and cigarette usage (FIELD et al., 2001), whereas depression is positively associated with cigarette usage (FERGUSSON et al., 1996).

This study further observed that there is a negative relationship between the prevalence of cigarette smoking and the likelihood to use alcohol, whilst alcohol users lower the unconditional mean level of monthly packs. Contrary to our findings, as reported by previous studies, there is a positive relationship between smoking and alcohol use, even if they trigger one another. (PIERANI \& TIEZZI, 2009; BILGIC et al., 2013). However, this is not valid for Muslim countries and it cannot be concluded that smokers do not drink alcohol due to their religious beliefs. We reported that alcohol consumers have less tendency $(10.4 \%)$ than those who do not consume 
alcohol. Looking at the consumption levels; although, the monthly conditional mean levels of cigarette packs increased with the use of alcohol, its parameter estimate was statistically insignificant. Conversely, the unconditional mean level of cigarette packs (1.96 packs) gets lower with alcohol consumption.

\section{CONCLUSION}

In this study, we used the data conducted by the Turkish Statistical Institute (TSI) on health with 35533 participants in 2012 in the country. These data complied with the IHS-DH censored demand model. The statistical significance of the crosscorrelation between tobacco use probability and levels indicates the use of simultaneous analysis of the factors that determine the likelihood of cigarette smoking and the quantity demanded. At the same time, the positive correlation coefficient between the two equations indicated that when one component of all non-system factors increases (or decreases) the likelihood of tobacco use, the monthly amount of tobacco consumption will increase (or decrease). In addition, the endogeneity problem caused by health variables was controlled in the system by using health variables together with their own remnants (residuals). In this respect, the results of the study showed that the methods to handle probability and level parameters in a system should be considered; and therefore, the Tobit model is incompatible with the data.

In this study, we determined the factors affecting both the decision and the amount of tobacco consumed by individuals. While many sociodemographic and economic factors were statistically significant in the decision to smoke and the amount of tobacco consumption, many health variables also have a deterrent effect. For example, both the probability of smoking and cigarette consumption will increase in the family with male heads and residing in urban areas. The creation of deterrent policies for such families may play a leading role in determining targeted smoking rates and consumption amounts in the country. When the age of the head of a family gradually increases, both the probability and the amount of cigarette consumption of the family first increase and then decrease, showing a nonlinear relationship. In this context, it would be more beneficial to have the target group of families especially including young and middle-aged generations in the measures policy packages to be created to curb cigarette consumption in the country. As the education level of the head of the family gradually increases, first, the probability of smoking and consumption level of the family increases and then decreases with higher education level presenting a nonlinear relationship. In this case, it can be envisaged that especially the families with high school graduates should have more place in the policies to be established to have effective deterrent measures against cigarette smoking across the country. While many individual chronic diseases in families reduce the likelihood and consumption of cigarettes, cigarette consumption increases as expected, especially in families with diseases such as depression. If this is the case then the state needs to develop activities to explain the harms of smoking for individuals with such diseases leading more of cigarette consumption.

In Turkey, when considering that $98 \%$ of the population is Muslim, the fact that the Presidency of Religious Affairs has made statements in recent years in the visual and written media that cigarette smoking is forbidden in Islam may at least have a positive impact on the conservative segment of the population in future. When human health is taken into consideration, the gradual spread of the detrimental effect of smoking on human health starting from primary school children to the whole education curriculum will have a positive impact on the future generation in the country. This attitude coincides with the findings of our education variable, i.e., as the level of education gradually increases, cigarette consumption increases at a decreasing rate. Conversely, it is extremely important that the Supreme Council of Religious Affairs should prepare public spots to curb the consumption of cigarettes, especially in the visual media, which may have a significant impact on society. Although, the Ministry of Health performs this kind of functionality in the country, it is extremely important that the Presidency of Religious Affairs should be a partner in this kind of action and have positive consequences for the conservative segments of the society. In future studies, one should focus on the simultaneous analysis of health variables with the tobacco consumption level with the help of the computer software programs (containing multi-dimension integral).

\section{ACKNOWLEDGEMENTS}

No financial support received.

DECLARATION OF CONFLICT
INTERESTS

The authors declare no conflict of interest. The founding sponsors had no role in the design of the study; in the 
collection, analyses, or interpretation of data; in the writing of the manuscript, and in the decision to publish the results.

\section{AUTHORS' CONTRIBUTIONS}

All authors contributed equally for the conception and writing of the manuscript. All authors critically revised the manuscript and approved of the final version.

\section{REFERENCES}

AKSOY, A. et al. Determinants of household alcohol and tobacco expenditures in Turkey. Journal of Family and Economic Issues, v.40, n.4, p.609-622, 2019. Available from: <https://doi. org/10.1007/s10834-019-09619-1>. Accessed: Nov. 13, 2019. doi: 10.1007/s10834-019-09619-1.

BILGIC, A.; YEN, S. T. Household food demand in Turkey: A twostep demand system approach. Food Policy, v.43, p.267-277, 2013 Available from: <https://doi.org/10.1016/j.foodpol.2013.09.004>. Accessed: Nov. 16, 2018. doi: 10.1016/j.foodpol.2013.09.004.

BILGIC, A.; YEN, S. T. Demand for meat and dairy products by Turkish households: a Bayesian censored system approach. Agricultural Economics, v.45, n.2, p.117-127, 2014. Available from: <https://doi.org/10.1111/agec.12019>. Accessed: Aug. 16, 2018. doi: 10.1111/agec.12019.

BILGIC, A.; YEN, S. T. Household alcohol and tobacco expenditures in Turkey: a sample-selection system approach. Contemporary Economic Policy, v.33, n.3, p.571-585, 2014. Available from: <https://doi.org/10.1111/coep.12093>. Accessed: Aug. 11, 2018. doi: 10.1111/coep.12093.

CAVELAARS, A. E. et al. Educational differences in smoking: international comparison. British Medical Journal, v.320, n.7242, p.1102-1107, 2000. Available from: <https://doi.org/10.1136/ bmj.320.7242.1102>. Accessed: Aug. 23, 2018. doi: 10.1136/ bmj.320.7242.1102.

CHATTERJEE, S.; HADI, A. S. Simple linear regression. Regression Analysis by Example, Fourth Edition, p.21-51, 2006.

FERGUSSON, D. M. Comorbidity between depressive disorders and nicotine dependence in a cohort of 16-year-olds. Archives of General Psychiatry, v.53, n.11,p.1043-1047, 1996. Available from: $<$ https://10.1001/archpsyc.1996.01830110081010>. Accessed: Nov. 21, 2018. doi: 10.1001/archpsyc.1996.01830110081010.

FIELD, T. et al. Adolescent depression and risk factors. Adolescence, v.36, n.143, p.491-498, 2001.

GARCÍA, J.; LABEAGA, J. M. Alternative approaches to modelling zero expenditure: an application to Spanish demand for tobacco. Oxford Bulletin of Economics and Statistics, v.58, n.3, p.489-506, 1996. Available from: <https://doi. org/10.1111/j.1468-0084.1996.mp58003004.x>. Accessed: Dec. 11, 2018. doi: 10.1111/j.1468-0084.1996.mp58003004.x.

GATS. Ministry of health, the global adult tobacco survey, Tobacco Survey, 2012.Avalible from: <http://www.halksagligiens. hacettepe.edu.tr/KYTA_TR.pdf $>$. Accessed: Nov. 1, 2018.

HISCOCK, R. et al. Socioeconomic status and smoking: a review. Annals of the New York Academy of Sciences, v.1248, n.1, p.107-123, 2012. Available from: <https://oi.org/10.111 1/j.1749-6632.2011.06202.x>. Accessed: Sep. 12, 2018. doi: 10.1111/j.1749-6632.2011.06202.x.

HM. Ministry of Health Ministry of Health of Republic of Turkey, Turkey public survey on smoking behavior and anti-smoking campaign. PYAR research limited partnership, 2007. Available from: $\quad<$ http://www.who.int/tobacco/surveillance/survey/gats/ report_tur 2012.pdf?ua\%BC1. Accessed: Nov. 07, 2018.

JEE, S. H. et al. Smoking and cancer risk in Korean men and women. Cancer Causes Control, v.15, n.4, p.341-348, 2004. Available from: <https://doi.org/10.1023/B:CACO. 0000027481.48153.97>. Accessed: Nov. 12, 2018. doi: 10.1023/B:CACO.0000027481.4815.

JONES, A. M. A double-hurdle model of cigarette consumption. Journal of Applied Econometrics, v.4, n.1, p.23-39, 1989. Available from: <https://doi.org/10.1002/jae.3950040103>. Accessed: Mar. 30, 2018. doi: 10.1002/jae.3950040103.

KILIC, D.; OZTURK, S. Gender differences in cigarette consumption in Turkey: evidence from the global adult tobacco survey. Health Policy, v.114, n.2, p.207-214, 2014. Available from: $<$ https://doi.org/10.1016/j.healthpol.2013.05.019>. Accessed: Sep. 10, 2018. doi: 10.1016/j.healthpol.2013.05.019.

LAMBERT, D. et al. Service use of rural and urban medicaid beneficiaries suffering from depression: the role of supply. The Journal of Rural Health, v.15, n.3, p.344-355, 1999. Available from: <https://doi.org/10.1111/j.1748-0361.1999. tb00756.x>. Accessed: Nov. 04, 2018. doi: 10.1111/j.17480361.1999.tb00756.x.

LINDSTRÖM, M. et al. Socioeconomic differences in smoking cessation: the role of social participation. Scandinavian journal of public health, v.28, n.3, p.200-208, 2000. Available from: <https:// doi.org/10.1177\%2F14034948000280030901>. Accessed: Mar. 22, 2018. doi: $10.1177 \% 2$ F14034948000280030901.

MACÍAS, F. et al. Different patterns by age-group and gender of socioeconomic inequalities in smoking in Colombia. Nicotine \& Tobacco Research, v.15, n.10, p.1745-55, 2013. Available from: $<$ https://doi.org/10.1093/ntr/ntt055>. Accessed: Sep. 20, 2018. doi: $10.1093 / \mathrm{ntr} / \mathrm{ntt} 055$.

OGUZTURK, B.; GULCU, S. Y. Analysis of factors effecting the consumption of cigarette in Turkey. Journal of Alanya Faculty of Business, v.4, n.2, p.99-105, 2012.

PALANIAPPAN, U. et al. Fruit and vegetable consumption is lower and saturated fat intake is higher among Canadians reporting smoking. The Journal of Nutrition, v.131, n.7, p.19528, 2001. Available from: <https://doi.org/10.1093/jn/131.7.1952>. Accessed: Mar. 22, 2018. doi: 10.1093/jn/131.7.1952.

PIERANI, P.; TIEZZI, S. Addiction and interaction between alcohol and tobacco consumption. Empirical Economics, v.37, n.1, p.1-23, 2009. Available from: <https://doi.org/10.1007/ s00181-008-0220-3>. Accessed: Nov. 22, 2018. doi: 10.1007/ s00181-008-0220-3.

SHAIK, B.; TEPOJU, M. A cross sectional community based study on the prevalence tobacco smoking (considering only cigarette and hookah smoking) among the urban youth. Andhra Pradesh Journal of Psychological Medicine, v.14, n.2, p.164-70, 2013. 
TSI,. Turkey Statistical Institute. Global adult tobacco survey tobacco use in Turkey, 2015. Available from: $<$ http://www.tuik. gov.tr/Start.do; jsessionid=1c2mYNGG17mV30Ylw5K9cnCJ900 J2GTx1nxNsLT7hyp9dC5G6yFF!-1641813149>. Accessed: Nov. $01,2018$.

TYAS, S. L.; PEDERSON, L.L. Psychosocial factors related to adolescent smoking: a critical review of the literature. Tobacco Control, v.7, n.4, p.409-420, 1998. Available from: <http://dx.doi. org/10.1136/tc.7.4.409>. Accessed: Sep. 12, 2018. doi: 10.1136/ tc.7.4.409.

WALDRON, I.; LYE, D. Employment, unemployment, occupation, and smoking. American Journal of Preventive Medicine, v.5, p.142-149, 1989. Available from: <https://doi.org/10.1016/S07493797(18)31095-X>. Accessed: Mar. 10, 2018. doi: 10.1016/ S0749-3797(18)31095-X.
WHO. World Health Organization. World health statistics 2013. Available from: <http://www.who.int/gho/publications/world health_statistics/2013/en/>. Accessed: Nov. 01, 2018.

WHO, World Health Organization. World health statistics 2015 Available from: <http://www.who.int/gho/publications/world health_statistics/2015/en/> Accessed: Sep. 04, 2018.

YEN, S. T. A multivariate sample-selection model: estimating cigarette and alcohol demands with zero observations. American Journal of Agricultural Economics, v.87, n.2, p.453-466, 2005 a. Available from: $<$ https://doi.org/10.1111/j.1467-8276.2005.00734.x $>$. Accessed: Aug. 18, 2018. doi: 10.1111/j.1467-8276.2005.00734.x.

YEN, S. T. Zero observations and gender differences in cigarette consumption. Applied Economics, v.37, n. 16, p.1839-1849, 2005b. Available from: <https://doi.org/10.1080/00036840500214322>. Accessed: Oct. 12, 2018. doi: 10.1080/00036840500214322. 